\title{
The efficacy and safety of aflibercept and conbercept in diabetic macular edema
}

This article was published in the following Dove Press journal:

Drug Design, Development and Therapy

\author{
Siwei Cai \\ Qianhui Yang \\ Xiaorong Li \\ Yan Zhang \\ Tianjin Medical University Eye \\ Hospital, Tianjin Medical University \\ Eye Institute, College of Optometry \\ and Ophthalmology, Tianjin Medical \\ University, Tianjin 300384, People's \\ Republic of China
}

\begin{abstract}
Diabetic macular edema (DME) has shown an increasing prevalence during the past years and is the leading cause of diabetic retinopathy blindness. Traditional treatment modalities include laser and corticosteroid therapy, which, however, either act through unclear mechanisms or cause cataracts and elevated intraocular pressure. In recent years, as the pathogenic role of VEGF in DME has been well-recognized, the intravitreal injection of anti-VEGF drugs has become the first-line treatment of DME due to their great efficacy in improving visual acuity and mitigating macular edema. Advantages have been shown for aflibercept and conbercept, the two recombinant decoy receptors that can bind VEGF with high specificity and affinity, in DME treatment in clinical trials conducted both worldwide and in People's Republic of China. This review introduces the structural characteristics and molecular mechanisms of action of these two anti-VEGF drugs, and summarizes the clinical trials evaluating their efficacy and safety, with the hope to provide clues for designing optimal and personalized therapeutic regimens for DME patients.
\end{abstract}

Keywords: diabetes, diabetic retinopathy, diabetic macular edema, therapy, aflibercept, conbercept, clinical trial, VEGF decoy receptor

\section{Introduction}

Diabetic macular edema (DME) has become the leading cause of vision loss in people with diabetes, and its prevalence is ascending on a global scale. ${ }^{1}$ In the US, nearly $4 \%$ of diabetic patients aged over 40 years have DME. ${ }^{2}$ Asia, the global epicenter of the diabetic epidemic, ${ }^{3}$ is also facing an increasing number of patients with DME. Moreover, vision loss substantially compromises patients' quality of life and capability of disease management. ${ }^{4}$ Therefore, effective treatments for DME are urgently needed. Three therapeutic modalities are available. First, laser therapy, including focal and grid laser, has been a standard treatment modality of DME for more than 3 decades. ${ }^{5,6}$ It reduces $50 \%$ of vision loss in patients with clinically significant DME, ${ }^{7}$ however, only $8.3 \%-25 \%$ of DME patients experience improvements in visual acuity (VA) following 2-3 years of laser treatment, ${ }^{8}$ and the mechanism of action of laser therapy remains elusive. ${ }^{9}$ Second, corticosteroid therapy, such as intravitreal injection of triamcinolone acetonide and long-acting dexamethasone implant, ${ }^{5,10-12}$ is an effective treatment modality for DME due to its anti-inflammatory functions. ${ }^{13,14}$ Nonetheless, the complications incurred limit its further applications. ${ }^{5,12,15}$

With the advent of recombinant protein technology and the discovery of pathogenic mechanisms underlying DME, anti-VEGF drugs have emerged and have become the first-line treatment for DME in recent years as they restore and stabilize vision in most DME patients. ${ }^{16,17}$ Several types of anti-VEGFs acting via different mechanisms are 
clinically available, including the full-length monoclonal antibody (mAb) to VEGF, bevacizumab (Avastin ${ }^{\circledR}$; Genentech, South San Francisco, CA, USA), the Fab fragment of the mAb to VEGF, ranibizumab (LUCENTIS ${ }^{\circledR}$; Novartis International AG, Basel, Switzerland), and the recombinant decoy receptors such as aflibercept $\left(\right.$ EYLEA $^{\circledR}$ or VEGF Trap-eye; Regeneron Pharmaceuticals, Inc., Tarrytown, NY, USA and Bayer, Berlin, Germany) and conbercept (Kanghong Biotech Company, Chengdu, Sichuan, People's Republic of China). ${ }^{18}$ Among these anti-VEGFs, the recombinant decoy receptors have shown remarkable efficacy and safety in clinical trials. This review aims to delineate structural and functional characteristics of aflibercept and conbercept, and to summarize and discuss the clinical data with regard to their efficacy and safety, as well as to compare the decoy receptor drugs with corticosteroid and anti-VEGF mAb drugs in the treatment of DME.

\section{Structural, biochemical, and pharmacological characterization of aflibercept and conbercept}

\section{Aflibercept}

Aflibercept is a $115 \mathrm{kDa}$ recombinant protein that fuses the second extracellular domain of human VEGFR-1 and the third extracellular domain of human VEGFR-2 with the Fc portion of human immunoglobulin $\operatorname{IgG} 1 .{ }^{19}$ It functions as a soluble decoy receptor that binds human VEGF-A, VEGF-B, and PIGF with high affinity (VEGF-A121, Kd =0.36 pM; VEGF-A165, Kd =0.50 pM; VEGF-B, Kd =1.92 pM; PIGF, $\mathrm{Kd}=38.9 \mathrm{pM}){ }^{20,21}$ The experimental results suggest that aflibercept's binding affinity to VEGF-A165 is almost 100-fold greater than ranibizumab and bevacizumab, which might be ascribed to the 3-dimensional configuration of its Fab fragment that favors the creation of an almost irreversible "two-fist" grasp on the target. ${ }^{20,22,23}$ These structural characteristics may, at least from a theoretical perspective, enable aflibercept to suppress neovascularization and vascular permeability caused by VEGF overexpression. The mechanism of action of aflibercept is to competitively inhibit the binding of VEGF to its cognate receptors, VEGFR-1 and VEGFR-2. ${ }^{20,24,25}$

The intravitreous half-life of aflibercept in humans has not been assessed, although the experiments in rabbits indicate a mean intravitreous half-life of 4.6 days, which is longer than that of ranibizumab (2.8 days) and bevacizumab (4.2 days) in the same animal model. ${ }^{26,27}$ On the other hand, a mathematical model predicts the intravitreous half-life of aflibercept in humans as approximately 4.8 days, which is similar to that measured in rabbits and still longer than the predictive value of ranibizumab (3.2 days). ${ }^{28}$

Ziv-aflibercept (Zaltrap ${ }^{\circledR}$, Sanofi-Aventis, Bridgewater, NJ, USA, and Regeneron Pharmaceuticals, Inc.) bears an identical structure to aflibercept, and has been approved by the US Food and Drug Administration (FDA) to treat metastatic colon cancer. It is manufactured with larger dose, lower concentration, and higher osmolarity than its counterpart for ocular administration. ${ }^{29,30}$

\section{Conbercept}

Conbercept is a $143 \mathrm{kDa}$ recombinant anti-VEGF fusion protein engineered from a full human cDNA sequence in Chinese hamster ovary cells. The Fab of conbercept comprises the second extracellular domain of VEGFR-1 and the third and fourth extracellular domains of VEGFR-2, which then fuses to the Fc of human IgG1. ${ }^{31-33}$ Conbercept also functions as a decoy receptor and binds all isoforms of VEGF-A (Kd for VEGF-A165 =0.5 pM), VEGF-B, VEGF-C, and PIGF with high affinity, precluding the activation of downstream signaling mediated by the VEGF family members. ${ }^{34}$ The structure of conbercept differs from aflibercept in that it incorporates the fourth extracellular domain of VEGFR-2 into the Fab. Although this domain is not directly involved in ligand binding, it facilitates receptor dimerization. ${ }^{35}$ The dimerized receptor binds VEGF 100-fold more tightly than the monomeric counterpart. ${ }^{36}$ Moreover, the fourth domain improves the receptor's 3-dimensional structure and enhances VEGF's association rate. Therefore, biochemical and pharmacological analyses indicate that conbercept's affinity to VEGF is 50-fold higher than that of bevacizumab. The structural characteristics provide a molecular basis for conbercept's anti-angiogenic functions in human umbilical vein endothelial cells. ${ }^{33,37,38}$

Similar to aflibercept, the intravitreous half-life of conbercept in humans has not been reported. However, it is 4.2 days in rabbit eye, which is close to aflibercept (4.8 days) and bevacizumab (4.2-6.6 days), but longer than ranibizumab (2.8 days). ${ }^{39-42}$

\section{Clinical trails}

\section{Efficacy and safety of aflibercept and conbercept in the treatment of DME Aflibercept}

A self-controlled pilot study conducted by do et $\mathrm{al}^{43}$ was reported in 2009. Five DME patients received a single intravitreal injection of $4.0 \mathrm{mg}$ aflibercept followed by 6-week observation. The results showed that aflibercept was 
well-tolerated with no ocular toxicity. At the fourth week following the injection, the median best-corrected visual acuity (BCVA) improved by nine Early Treatment of Diabetic Retinopathy Study (ETDRS) letters read at $4 \mathrm{~m}$ distance (Snellen equivalent 20/50); the median excess central $1 \mathrm{~mm}$ foveal thickness (FTH) was reduced from $108 \mu \mathrm{m}$ at baseline to $59 \mu \mathrm{m}$. At 6 weeks after the injection, four of the five patients showed improved BCVA (median improvement of three letters) and excess FTH (median $74 \mu \mathrm{m} ; 31 \%$ reduction from baseline, $P=0.063$ ) (Table 1).

Another prospective study was reported by Campos et $\mathrm{al}^{44}$ in 2018, which evaluated the efficacy of aflibercept. Fifteen anti-VEGF-naïve DME patients were recruited and received intravitreal injections of aflibercept (IVA) at $2 \mathrm{mg}$, 5-monthly doses followed by the same dose every 2 months for 1 year. BCVA improvement was observed at the second visit after the loading doses. At 12 months after the initial injection, the mean BCVA improved from 47.3 \pm 14.2 ETDRS letters at baseline to $62.2 \pm 13.9$ ETDRS letters $(P<0.001)$ (Table 1). All eyes (100\%) gained ETDRS letters, $89.6 \%$ of the eyes gained $\geq 10$ letters, $65.5 \% \geq 15$ letters, and $6.9 \% \geq 20$ letters. The central macular thickness (CMT) was significantly reduced from a mean of $460.5 \pm 11.8 \mu \mathrm{m}$ at baseline to $229.0 \pm 43.8 \mu \mathrm{m}(P<0.001)$ (Table 1). No adverse events occurred in this study.

In 2016, Andrade et $\mathrm{al}^{45}$ reported a short-term, prospective clinical trial assessing the efficacy and safety of intravitreal injection of ziv-aflibercept (IVZA) in DME therapy. Seven patients with DME received IVZA every 4 weeks for 6 months. During the follow-up, the mean logarithm of the minimum angle of resolution (logMAR) of the BCVA improved 0.55 $\pm 0.19 \log$ MAR units $(P<0.001)$ and the mean central retinal thickness (CRT) reduced 125.86 $\pm 65.46 \mu \mathrm{m}$ $(P=0.002)$, and there was no systemic or ocular complication (Table 1).

\section{Conbercept}

In 2018, a retrospective study ${ }^{46}$ was reported which evaluated the therapeutic efficacy of conbercept for treatment of DME patients with different baseline VA. A total of 107 patients were divided into four groups according to their baseline BCVA: conbercept-treated subgroup with worse baseline VA (less than 69 letters), untreated subgroup with worse baseline VA, conbercept-treated subgroup with better baseline VA (78-69 letters), untreated subgroup with better baseline VA. Patients received one initial intravitreal injection of conbercept (IVC) followed by retreatment based on BCVA loss or CMT increase. At $12 \mathrm{~m}$, the mean improvement in BCVA was significantly greater in the conbercept-treated groups than that of the corresponding untreated controls $(18.0 \pm 15.0$ letters vs $-4.0 \pm 6.0$ letters, $P<0.001$ for worse baseline BCVA groups; $7.0 \pm 1.0$ letters vs $-5.0 \pm 5.0$ letters, $P<0.001$ for better baseline BCVA groups) (Table 1). In addition, the mean CMT was significantly reduced in the conbercept treatment groups as compared to that of the corresponding untreated controls ( $-212.8 \pm 11.9 \mathrm{vs}-44.3 \pm 35.3 \mu \mathrm{m}, P<0.001$ for worse baseline BCVA groups; $-116.1 \pm 88.9$ vs $-33.7 \pm 49.8 \mu \mathrm{m}$, $P=0.001$ for better baseline BCVA groups) (Table 1). It is notable that the BCVA improvement and CMT reduction in the treated group with worse baseline VA were more prominent than that in the treated group with better baseline VA $(P<0.001)$, however, the two groups had no significant difference in the number of injections $(6.7 \pm 0.9$ injections in the worse baseline VA group vs $6.5 \pm 1.1$ injections in better baseline VA group, $P=0.350$ ) (Table 1).

Together, these studies have indicated that thus far all the VEGF decoy receptors, including aflibercept, ziv-aflibercept, and conbercept have shown safe and effective profiling in DME treatment. Conbercept may have better efficacy for eyes with worse baseline VA than those with better baseline VA with similar number of injections.

\section{Comparison of aflibercept to laser therapy} The DA VINCI study ${ }^{47}$ is a randomized, double-masked, multicenter, Phase II clinical trial that aimed to compare the efficacy of aflibercept at different dosing with traditional laser photocoagulation in eyes with DME. Two hundred and twenty-one diabetic patients with center-involved DME were enrolled and randomized into five groups: $0.5 q 4$ group that received IVA $0.5 \mathrm{mg}$ every 4 weeks; $2 \mathrm{q} 4$ group that received IVA 2 mg every 4 weeks; 2q8 group that received IVA $2 \mathrm{mg}$ every 8 weeks after three initial monthly doses; 2PRN group that received IVA $2 \mathrm{mg}$ as needed (PRN) after three initial monthly doses; and laser group that received macular laser photocoagulation. At 24 weeks, the mean VA improvements in the four aflibercept groups, ranging from 8.5-11.4 ETDRS letters, were significantly greater than that in the laser group (2.5 letters; $P=0.009$ for each IVA group vs laser group) (Table 2). Moreover, aflibercept maintained or augmented the VA improvements to the $52^{\text {nd }}$ week $(11.0,13.1,9.7$, and 12.0 letters in $0.5 q 4,2 q 4,2 q 8$, and $2 P R N$ groups, respectively); in contrast, the VA in the laser group deteriorated 1.3 letters during the same period. The percentages of the patients with VA gain of 0,10 , and 15 letters were $93 \%, 64 \%$, and $34 \%$ in the aflibercept groups as compared to $68 \%, 32 \%$, and $21 \%$ in the laser group, respectively. The proportions 


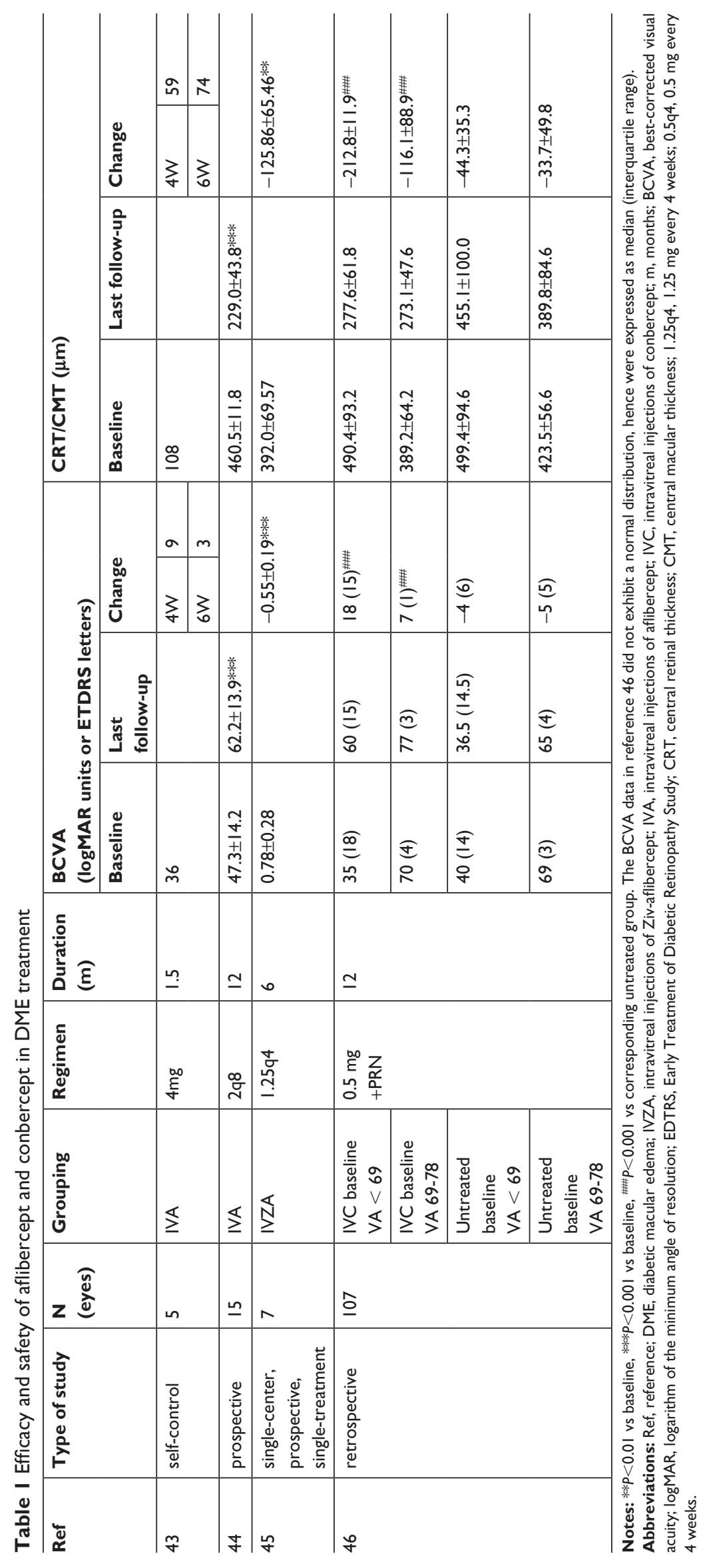


Table 2 Comparisons of aflibercept with laser photocoagulation in DME treatment

\begin{tabular}{|c|c|c|c|c|c|c|c|c|}
\hline \multirow[t]{2}{*}{ Study } & \multirow[t]{2}{*}{ Ref } & \multirow{2}{*}{$\begin{array}{l}\text { Duration } \\
\text { (w) }\end{array}$} & \multirow[t]{2}{*}{ Regimen } & \multirow{2}{*}{$\begin{array}{l}\mathbf{N} \\
\text { (eyes) }\end{array}$} & \multicolumn{2}{|c|}{ BCVA (ETDRS letters) } & \multicolumn{2}{|l|}{ CRT $(\mu \mathrm{m})$} \\
\hline & & & & & Baseline & Change & Baseline & Change \\
\hline $\mathrm{DA} \mathrm{VINCl}$ & 47 & 24 & $\begin{array}{l}\text { IVA } 0.5 q 4 \\
\text { IVA } 2 q 4 \\
\text { IVA 2q8 } \\
\text { IVA 2PRN } \\
\text { Laser }\end{array}$ & $\begin{array}{l}44 \\
44 \\
42 \\
45 \\
44\end{array}$ & $\begin{array}{l}59.3 \pm 11.2 \\
59.9 \pm 10.1 \\
58.8 \pm 12.2 \\
59.6 \pm 11.1 \\
57.6 \pm \mid 2.5\end{array}$ & $\begin{array}{l}8.6 * * \\
11.4^{* * * *} \\
8.5^{* *} \\
10.3^{* * * *} \\
2.5\end{array}$ & $\begin{array}{l}426.1 \pm 128.3 \\
456.6 \pm 135.0 \\
434.8 \pm 111.8 \\
426.6 \pm 152.4 \\
440.6 \pm 145.4\end{array}$ & $\begin{array}{l}-144.6 * * * \\
-194.5 * * * * \\
-127.3 * * \\
-153.3 * * * * \\
-67.9\end{array}$ \\
\hline VISTA & 16 & $\begin{array}{l}52 \\
100\end{array}$ & $\begin{array}{l}\text { IVA 2q4 } \\
\text { IVA 2q8 } \\
\text { Laser } \\
\text { IVA 2q4 } \\
\text { IVA 2q8 } \\
\text { Laser } \\
\text { IVA 2q4 } \\
\text { IVA 2q8 } \\
\text { Laser }\end{array}$ & $\begin{array}{l}154 \\
151 \\
154 \\
154 \\
151 \\
154 \\
154 \\
151 \\
154\end{array}$ & $\begin{array}{l}58.9 \pm 10.8 \\
59.4 \pm 10.9 \\
59.7 \pm 10.9\end{array}$ & $\begin{array}{l}12.5 * * * * \\
10.7 * * * * \\
0.2 \\
11.5^{* * * *} \\
11.7^{* * * *} \\
6.3 \\
10.4^{* * * *} \\
10.5 * * * * \\
1.4\end{array}$ & $\begin{array}{l}485 \pm 157 \\
479 \pm 154 \\
483 \pm 153\end{array}$ & $\begin{array}{l}-185.9^{* * * * *} \\
-183.1^{* * * *} \\
-73.3 \\
-191.4^{* * * *} \\
-191.1^{* * * *} \\
-83.9 \\
-200.4^{* * * *} \\
-190.1^{* * * *} \\
-109.8\end{array}$ \\
\hline VIVID & $\begin{array}{l}50 \\
16\end{array}$ & $\begin{array}{l}52 \\
100 \\
148\end{array}$ & $\begin{array}{l}\text { IVA 2q4 } \\
\text { IVA 2q8 } \\
\text { Laser } \\
\text { IVA 2q4 } \\
\text { IVA 2q8 } \\
\text { Laser } \\
\text { IVA 2q4 } \\
\text { IVA 2q8 } \\
\text { Laser }\end{array}$ & $\begin{array}{l}136 \\
135 \\
132 \\
136 \\
135 \\
132 \\
136 \\
135 \\
132\end{array}$ & $\begin{array}{l}60.8 \pm 10.7 \\
58.8 \pm 11.2 \\
60.8 \pm 10.6\end{array}$ & $\begin{array}{l}10.5^{* * * *} \\
10.7^{* * * * *} \\
1.2 \\
11.8^{* * * *} \\
10.6 * * * \\
5.5 \\
10.3^{* * * *} \\
11.7^{* * * *} \\
1.6\end{array}$ & $\begin{array}{l}502 \pm 144 \\
518 \pm 147 \\
540 \pm 152\end{array}$ & $\begin{array}{l}-195.0^{* * * * *} \\
-192.4^{* * * * *} \\
-66.2 \\
-211.8^{* * * *} \\
-195.8^{* * * *} \\
-85.7 \\
-215.2^{\text {**** }} \\
-202.8^{\text {**** }} \\
-122.6\end{array}$ \\
\hline
\end{tabular}

Note: ${ }^{* * P}<0.01$ vs laser, ${ }^{*} * * P<0.001$ vs laser, ${ }^{*} * * * P<0.0001$ vs laser. The specific data of DA VINCl study at 52 week are not available from the literature (Ref 48 ), hence are not listed in this table.

Abbreviations: Ref, reference; w, weeks; BCVA, best-corrected visual acuity; EDTRS, Early Treatment of Diabetic Retinopathy Study; CRT, central retina thickness; IVA, intravitreal injections of aflibercept; $0.5 q 4,0.5 \mathrm{mg}$ every 4 weeks; $2 q 4,2 \mathrm{mg}$ every 4 weeks; $2 q 8,2 \mathrm{mg}$ every 8 weeks; 2 PRN, $2 \mathrm{mg}$ as needed.

of eyes with VA gain of more than 15 letters in individual aflibercept groups $(40.9 \%, 45.5 \%$, and $42.2 \%$ in $0.5 \mathrm{q} 4,2 \mathrm{q} 4$, and $2 \mathrm{PRN}$ groups, respectively) were significantly higher than that in the laser group $(11.4 \% ; P=0.003$ for $0.5 \mathrm{q} 4$ vs laser; $P=0.001$ for $2 \mathrm{q} 4$ vs laser; $P=0.002$ for $2 \mathrm{PRN}$ vs laser) at the $52^{\text {nd }}$ week (Table 2). Consistent with the VA improvements, the mean reductions in CRT in the aflibercept groups, ranging from 127.3-194.5 $\mu \mathrm{m}$, were 2-fold greater than that in the laser group $(67.9 \mu \mathrm{m}, P=0.007$ for each aflibercept group vs laser) after 24 -week treatment ${ }^{48}$ and the superiority of aflibercept was sustained to the $52^{\text {nd }}$ week $(165.4,227.4$, 187.8, and $180.3 \mu \mathrm{m}$ in $0.5 \mathrm{q} 4,2 \mathrm{q} 4,2 \mathrm{q} 8$, and 2 PRN IVA groups, respectively; $58.4 \mu \mathrm{m}$ in laser group; all $P<0.001$, each aflibercept group vs laser) (Table 2). ${ }^{48}$

Moreover, a sub-study selected 46 patients from this clinical trial to evaluate retinal sensitivity ${ }^{49}$ Retinal sensitivity was measured by fundus-monitored microperimetry and compared in one (central), five (one central and four inner), and eight (four inner and four outer) subfields of optical coherence tomography (OCT). At the $52^{\text {nd }}$ week, the mean VA improvements in the aflibercept groups, ranging from 5.4-16.3 letters, were significantly greater than in the laser group (3.3 letters). The retinal sensitivity in the laser group was similar to the baseline level in the central OCT subfield and even reduced in the five and eight OCT subfields; in contrast, the $2 \mathrm{q} 8$ group and the pooled aflibercept group exhibited significantly higher retinal sensitivities in the five and eight OCT subfields than the laser group (both $P<0.050)$. The results of DA VINCI study suggest that IVA can generate and maintain greater improvements in VA and CRT than laser photocoagulation; additionally, IVA, but not laser photocoagulation, improves retinal sensitivity in selected patients.

Another two similar clinical trials, the VISTA and VIVID studies ${ }^{50}$ were double-masked, randomized, Phase III trials. These trials were performed to compare the efficacy of aflibercept with laser in DME patients. Eight hundred and seventy-two DME patients with central involvement were included and received either IVA $2 \mathrm{q} 4$ or $2 \mathrm{q} 8$ after five initial monthly doses, or macular laser photocoagulation. After 52-week treatment, mean VA gains in the IVA groups (12.5 letters in 2q4, 10.7 in 2q8 in VISTA; 10.5 in 2q4, 10.7 
in 2 q8 in VIVID) were significantly greater than those in the laser group in both studies (0.2 letters in VISTA, 1.2 letters in VIVID, all $P<0.001$ for IVA vs laser) (Table 2). ${ }^{50}$ The greater VA benefits in the IVA groups were maintained to the $100^{\text {th }}$ week $(11.5,11.1$, and 0.9 letters in $2 q 4,2 q 8$, and laser groups, respectively, all $P<0.001$ in VISTA; 11.4, 9.4, and 0.7 letters in $2 \mathrm{q} 4,2 \mathrm{q} 8$, and laser groups, respectively, all $P<0.001$ in VIVID) (Table 2), ${ }^{16}$ and even to the $148^{\text {th }}$ week $(10.4,10.5$, and 1.4 letters in $2 q 4,2 q 8$, and laser groups, respectively, all $P<0.001$ in VISTA; $10.3,11.7$, and 1.6 letters in $2 \mathrm{q} 4,2 \mathrm{q} 8$, and laser groups, respectively, all $P<0.001$ in VIVID) (Table 2). ${ }^{51}$ Meanwhile, the proportions of eyes that gained more than 15 letters in the IVA groups (41.6\% and $31.1 \%$ in $2 \mathrm{q} 4$ and $2 \mathrm{q} 8$ groups, respectively in VISTA; $32.4 \%$ and $33.3 \%$ in $2 \mathrm{q} 4$ and $2 \mathrm{q} 8$ groups, respectively in VIVID) were approximately 2-3-fold more than those in the laser groups $\left(7.8 \%\right.$ in VISTA; $9.1 \%$ in VIVID) at the $52^{\text {nd }}$ week. The superiority was sustained until the $100^{\text {th }}$ week $(38.3 \%$, $33.1 \%$, and $13.0 \%$ in $2 q 4,2 q 8$, and laser, respectively, all $P<0.001$ in VISTA; $38.2 \%, 31.1 \%$, and $12.1 \%$ in $2 \mathrm{q} 4$, $2 \mathrm{q} 8$, and laser, respectively, all $P<0.001$ in VIVID) and the $148^{\text {th }}$ week $(42.9 \%, 35.8 \%$, and $13.6 \%$ in $2 q 4,2 q 8$, and laser, respectively, all $P<0.001$ in VISTA; $41.2 \%, 42.2 \%$, and $18.9 \%$ in $2 \mathrm{q} 4,2 \mathrm{q} 8$, and laser, respectively, $P<0.001$ in VIVID). Anatomically, the mean reductions in CRT in the IVA groups (185.9 and $183.1 \mu \mathrm{m}$ in $2 \mathrm{q} 4$ and $2 \mathrm{q} 8$, respectively in VISTA; 195.0 and $192.4 \mu \mathrm{m}$ in $2 \mathrm{q} 4$ and $2 \mathrm{q} 8$, respectively in VIVID) were significantly greater than those in the laser group (73.3 $\mu \mathrm{m}, P<0.001$ in VISTA; $66.2 \mu \mathrm{m}, P<0.001$ in VIVID) at the $52^{\text {nd }}$ week (Table 2). Furthermore, IVA groups had substantially higher percentages of eyes gaining more than 2-step improvements in the Diabetic Retinopathy Severity Scale (DRSS) score than the laser group $(37.0 \%$ in $2 \mathrm{q} 4,37.1 \%$ in $2 \mathrm{q} 8,15.6 \%$ in laser, all $P<0.001$ in VISTA; $29.3 \%$ in $2 \mathrm{q} 4,32.6 \%$ in $2 \mathrm{q} 8,8.2 \%$ in laser, $P=0.000$ in VIVID) (Table 2). ${ }^{16}$ This advantage in the aflibercept groups was maintained to the $148^{\text {th }}$ week $(29.9 \%$ in $2 q 4,34.4 \%$ in $2 \mathrm{q} 8,20.1 \%$ in laser, $P=0.035$ for $2 \mathrm{q} 4$ vs laser, $P=0.0052$ for $2 \mathrm{q} 8$ vs laser in VISTA; $44.3 \%$ in $2 \mathrm{q} 4,47.8 \%$ in $2 \mathrm{q} 8,17.4 \%$ in laser, both $P<0.001$ in VIVID) (Table 2). ${ }^{51}$

More recently, a Phase IV, ENDURANCE extension study was performed to determine whether the efficacy and safety achieved by $2.0 \mathrm{mg}$ IVA for DME during the Phase III VISTA trial could be maintained by an individualized, PRN regimen. ${ }^{52}$ Sixty patients who completed VISTA were selected to receive IVA in the presence of clinically relevant DME. During the 12-month follow-up, mean values of 4.5 times IVA were administered. Eighteen (30\%) patients required no IVA, and mean values of 6.0 times IVA were administered to those in need. Both the BCVA and CRT were stable. The mean BCVA improvements were less than 1.5 letters from baseline at all the time points examined. In addition, 37 (62\%) patients were also treated with laser, and there was no significant difference in the IVA frequency prior to and post-macular laser treatment. ${ }^{52}$

Collectively, these series of studies are well-designed, stringently-controlled, large-scale, and long-term clinical trials that demonstrate superiority of IVA to laser therapy with convincing evidence. IVA was better than laser at improving BCVA, reducing CRT, and maintaining retinal sensitivity in DME patients. These advantages were sustained as long as 148 weeks. Besides, IVA generated a greater percentage of patients with high DRSS score than laser therapy, and it is also suitable for further maintenance therapy with a personalized PRN regimen.

\section{Combination of conbercept with laser therapy}

Up to date, there is no clinical trial comparing the therapeutic efficacy of conbercept with laser in the treatment of DME. However, a few clinical trials studying the therapeutic efficacy of combining conbercept with laser therapy have been reported. A retrospective study involving 51 patients was conducted in 2016 to compare the efficacy of IVC plus grid laser photocoagulation (GLP) with IVC alone in the treatment of diffuse DME. ${ }^{53}$ At 12 months after therapy, the mean BCVA improved 9.1 \pm 4.5 letter score in the IVC group and $7.5 \pm 4.2$ letter score in the combination group. The mean CRT reduced $145.1 \pm 69.9 \mu \mathrm{m}$ in the IVC group and $168.5 \pm 53.6 \mu \mathrm{m}$ in the combination group. Even though the differences in the BCVA improvement $(P=0.164)$ and CRT reduction $(P=0.149)$ between the two groups were not significant, the average injection frequency in the IVC group (5.6 \pm 0.8 injections/eye) was significantly more $(P<0.001)$ than the combination group $(3.3 \pm 1.2$ injections/eye). The results of this study indicate that the combinatorial therapy, IVC plus laser, might be a better modality than the solitary IVC. Although the combination therapy did not show significantly superior efficacy compared to mere IVC, the combined laser therapy did facilitate a reduction in injection frequency, which implicates that the combinatorial strategy may incur less adverse effects and costs than IVC alone.

A prospective, randomized controlled trial was performed to evaluate the therapeutic effects of panretinal 
photocoagulation (PRP) therapy followed by IVC or posterior sub-Tenon's triamcinolone acetonide (STTA) therapy on DME at proliferative stage. ${ }^{54}$ The DME patients at proliferative stage were initially treated with PRP, and then divided into two groups: group A was treated with IVC $0.5 \mathrm{mg}$, group B with STTA $40 \mathrm{mg}$ (twice/2 weeks) during the first phase (1 month). The interventions were exchanged during the second phase ( 2 months) between the two groups. No treatment was given during the third phase (3-6 months). The results demonstrated that during the first phase, BCVA improved from $0.2 \pm 0.2$ to $0.4 \pm 0.2(F=5.880, P=0.004)$ in group $\mathrm{A}$, and from $0.2 \pm 0.2$ to $0.3 \pm 0.2(F=0.760, P=0.410)$ in group $\mathrm{B}$. The CMT reduced from $449.0 \pm 155.1$ to $304.1 \pm 84.7 \mu \mathrm{m}(F=14.900$, $P<0.01)$ in group $\mathrm{A}$, and from $463.8 \pm 152.9$ to $366.0 \pm 115.4 \mu \mathrm{m}$ $(F=3.700, P<0.03)$ in group B. The improvement in BCVA was better in group $\mathrm{A}(P<0.05)$ during this phase. In the second phase, the BCVA continued to rise to $0.5 \pm 0.3$ $(F=0.260, P<0.01)$ in group $\mathrm{A}$ and to the same extent $(F=0.310, P<0.01)$ in group B. The CMT was decreased to $260.7 \pm 63.0 \mu \mathrm{m}(F=-188.300, P<0.01)$ in group $\mathrm{A}$ and to $261.9 \pm 50.2 \mu \mathrm{m}(F=-201.900, P<0.01)$ in group B. No significant difference was found in the therapeutic effects between the two groups $(P>0.05)$ during this phase. In the third phase, the improvements in BCVA and CMT were sustained in both groups, BCVA was $0.4 \pm 0.3(F=0.220$, $P=0.001)$, and CMT 267.8 $\pm 58.3 \mu \mathrm{m}(F=-0.270, P<0.01)$ in group A; these two parameters were $0.5 \pm 0.3(F=-0.270$, $P<0.01)$ and $272.7 \pm 49.2 \mu \mathrm{m}(F=-191.1, P<0.01)$, respectively, in group B. Based on the results of this study, PRP plus IVC might be a better therapeutic strategy than PRP plus STTA in treating DME at proliferative stage.

\section{Combination of ranibizumab or bevacizumab with laser therapy}

Despite the fact that no study has reported on the efficacy of aflibercept combined with laser therapy in DME, several small-scaled clinical trials around the globe have examined the efficacy of combining ranibizumab with laser. However, the results are controversial. For example, in a single-arm, open-label, prospective clinical study conducted at four sites in Japan, DME patients were subjected to 2-monthly intravitreal injections of ranibizumab (IVRs) followed by PRN IVR in which IVR was performed when the CMT exceeded $300 \mu \mathrm{m}$. One week after each IVR, short pulse focal/grid laser was delivered to treat residual leakage outside the fovea $(>500 \mu \mathrm{m})$. Six months later, both the BCVA and CMT in these patients were significantly improved, and it was also indicated that the laser photocoagulation could reduce the number of IVRs required to realize the functional and anatomical improvements. ${ }^{55}$ In contrast, in a multicenter, prospective, randomized controlled clinical trial conducted in the US, angiography-guided macular laser photocoagulation was combined with a treat-and-extend regimen of IVR $0.3 \mathrm{mg}$. At the 1 year endpoint, the treat-and-extend regimen significantly reduced the number of IVRs compared with the monthly IVR $0.3 \mathrm{mg}$ regimen, however, the laser modality neither improved the efficacy of IVR ( $P=0.8$ for BCVA; $P=0.47$ for $\mathrm{CRT}$ ), nor reduced the number of ranibizumab injections (10.7 for IVR treat and extend vs 10.1 for IVR treat and extend plus laser) ${ }^{56}$ Such discrepancy might be due to the different dosing and regimens of IVR used in the trials, or due to the responses from distinct ethnic groups to the IVR and laser. It could also indicate that the combination of ranibizumab with laser might be more beneficial in short-term administration.

On the other hand, in a randomized three-arm clinical trial conducted in Egypt in 2010, the therapeutic modality combining intravitreal injection of bevacizumab (IVB) and sequential modified grid laser photocoagulation (MGP) appeared to be superior to IVB or MGP alone in reducing macular thickening and improving VA. Nonetheless, the BCVA improvements that had been generated by all the modalities disappeared at 6 months posttreatment. ${ }^{57}$ Moreover, retrospective clinical research in the US showed that IVB alone at 24 months after the treatment was better than both GLP alone and IVB plus GLP at reducing CMT in the patients with diffuse DME. ${ }^{58}$ Together, these results implicate that the combined modality of IVR or IVB plus laser might be used as a short-term $(<6$ months $)$ therapeutic intervention for DME.

\section{Comparison of aflibercept or conbercept to other drugs Comparison of aflibercept to dexamethasone implant}

The anti-VEGF drugs have shown superiority to laser therapy in the treatment of DME; however, due to the high prevalence of this disease, the costs involved during treatment have to be considered. A systematic review of literature reports that during a 3-year treatment period, the anti-VEGFs, such as ranibizumab and aflibercept, are more expensive than longacting corticosteroid implants. ${ }^{59}$ Therefore, an observational, retrospective study was conducted recently in Spain to 
compare IVA vs sequential dexamethasone implant followed by IVA in naïve DME patients. ${ }^{60}$ Fifteen patients in the IVA group were treated with aflibercept monthly for the first 5 months; whereas another 15 patients in the dexamethasone group were initially treated with a single dexamethasone implant (OZURDEX; Allergan plc, Dublin, Ireland), then both groups received IVA every 2 months. At the 12 months endpoint, the results showed that BCVA increased from $70.8 \pm 4.1$ to $83.5 \pm 2.7$ letters and from $75.6 \pm 2.7$ to $86.5 \pm 2.5$ letters in IVA and dexamethasone groups, respectively $(P=0.551)$. CMT decreased from $411.0 \pm 26.1$ to $288.1 \pm 10.5 \mu \mathrm{m}$ and from $411.4 \pm 24.3$ to $260.8 \pm 17.9 \mu \mathrm{m}$ in IVA and dexamethasone groups, respectively. No statistical significance was found between the two groups in BCVA or CMT changes (both $P>0.05$ ). Therefore, the sequential treatment, dexamethasone implant followed by IVA, could serve as a more costeffective yet equally efficacious alternative to the mere IVA regimen. ${ }^{60}$

\section{Comparison of aflibercept to bevacizumab and ranibizumab}

In order to compare the clinical efficacy and safety of IVA, IVB, and IVR in the treatment of DME, a randomized controlled clinical trial called the DRCR.net Protocol T study ${ }^{61}$ was conducted by Wells et al in the US. Six hundred and sixty patients with DME from 89 clinical centers were randomly divided into three groups and received IVA $(2.0 \mathrm{mg})$, IVB $(1.25 \mathrm{mg})$, or IVR $(0.3 \mathrm{mg})$ every 4 weeks, respectively. The results showed that all the anti-VEGF drugs improved the VA letter scores during the first year, and the mean score gains in the IVA group (13.3) were significantly greater than those in the IVB (9.7) and IVR (11.2) groups $(P<0.001$, IVA vs IVB; $P=0.03$, IVA vs IVR) (Table 3 ).

However, when taking the baseline VA letter score into account, the conclusion changed. In patients with mild baseline VA letter score (78-69; Snellen equivalent 20/32-20/40), the VA improvements were similar among the IVA (8.0 letter score), IVB (7.5 letter score), and IVR (8.3 letter score) groups both during the first and second year (IVA 7.8, IVB 6.8, and IVR 8.6 letter score, all $P>0.100$, for pair-wise comparisons) (Table 3) ${ }^{62}$ Furthermore, when patients with mild baseline VA were categorized by central subfield thickness (CST) at baseline, the IVB was significantly less beneficial than IVA and IVR during the first year in patients with CST more than $400 \mu \mathrm{m}$ (IVA 9.5, IVB 5.4, and IVR 9.5 letter score) (Table 3). ${ }^{63}$ On the other hand, in patients with worse baseline VA letter score (less than 69, Snellen equivalent 20/50 or worse), the IVA showed greater VA improvement

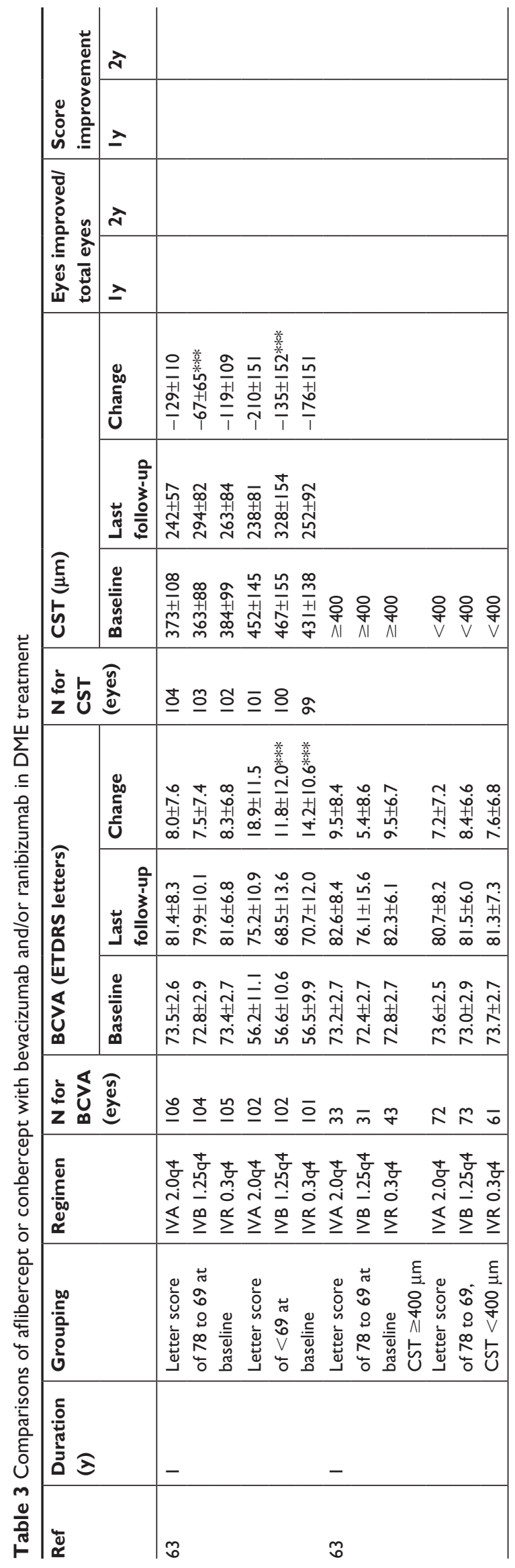




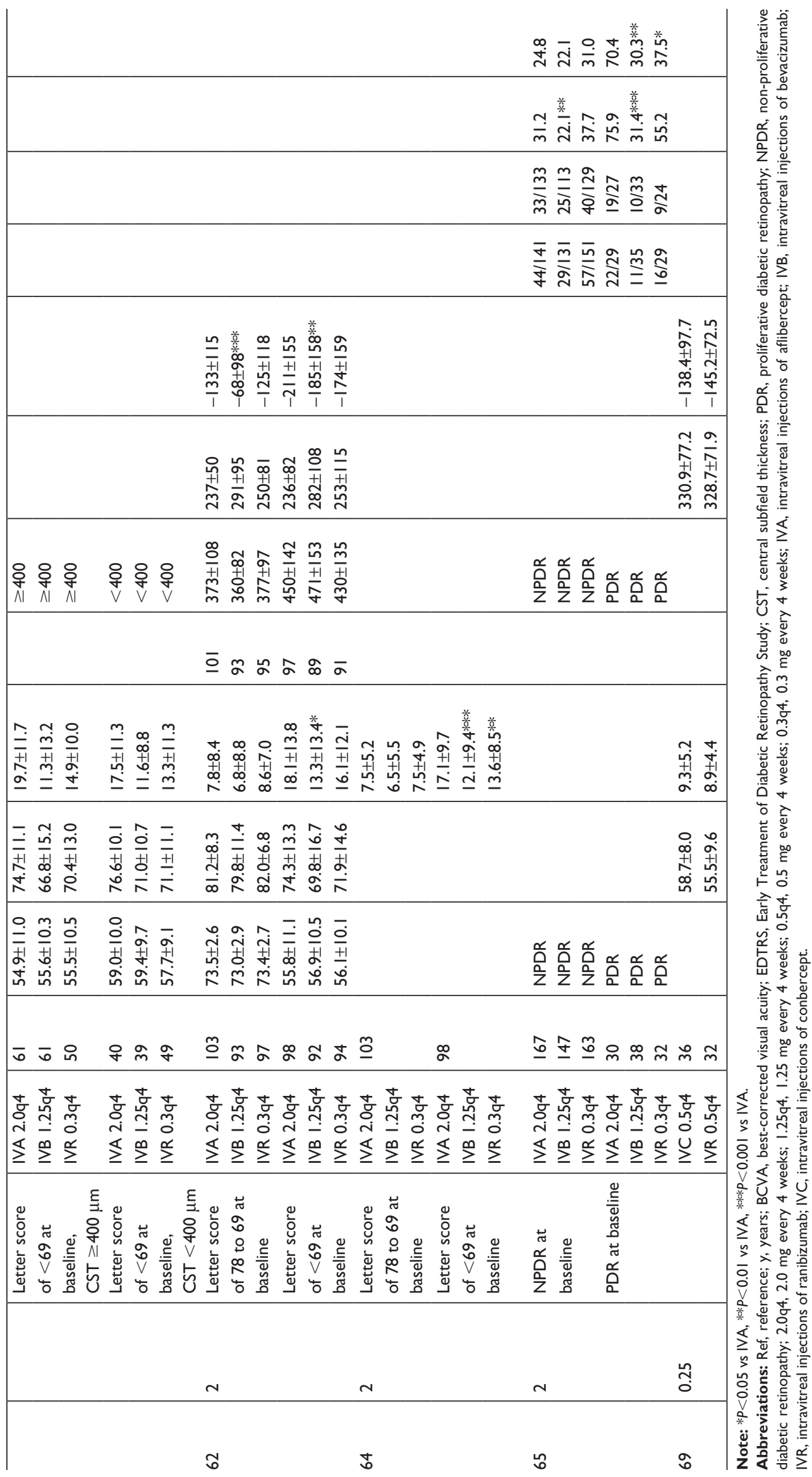


(18.9 letter score) than IVB and IVR (11.8 and 14.2 letter score, respectively; $P<0.001$ for IVA vs IVB; $P=0.003$ for IVA vs IVR) regardless of the baseline CST during the first year (Table 3). ${ }^{61,63}$ The IVA's superiority to IVB, but not IVR, was maintained during the second year (IVA 18.3, IVB 13.3, IVR 16.1 letter score; IVA vs IVB, $P=0.020$; IVA vs IVR, $P=0.180$ ) (Table 3). ${ }^{62}$ Anatomically, IVB reduced less CST than the other agents during the first year in the patients with worse baseline VA, but such difference was reduced during the second year (Table 3). ${ }^{64}$

In 2017, the data of this clinical trial were reanalyzed, and the effects of these three drugs on severity of diabetic retinopathy (DR) were reported. ${ }^{65}$ After 1-year treatment, $31.2 \%, 22.1 \%$, and $37.7 \%$ of the eyes with nonproliferative DR that had been treated with IVA, IVB, and IVR, respectively, exhibited improvements in DR severity, with IVA and IVR being more beneficial than IVB $(P=0.004$ for IVA vs IVB; $P=0.010$ for IVR vs IVB). The amelioration of DR severity was sustained to the second year $(24.8 \%$, $22.1 \%$, and $31.0 \%$ of eyes for IVA, IVB, and IVR, respectively), yet there was no significant difference among the groups. For the eyes with proliferative DR (PDR), aflibercept improved the disease severity more than the other drugs (IVA $75.9 \%$, IVB $31.4 \%$, and IVR $55.2 \% ; P<0.001$ for IVA vs IVB; $P=0.020$ for IVA vs IVR) during the first year, and this advantage was maintained during the second year (Table 3).

Results of this study suggest that all the three anti-VEGF drugs are effective in improving VA and DR severity in DME patients. Furthermore, aflibercept generates greater VA protective effects than bevacizumab and ranibizumab in DME patients with a baseline VA of less than 20/50, and it is also superior to mAbs in relieving disease severity in PDR patients. Nevertheless, it should be noted that the dosing of ranibizumab used in the US is $0.3 \mathrm{mg}$ /injection, which is different than the dosing of $0.5 \mathrm{mg} /$ injection in other countries. According to the pooled results of RISE and RIDE clinical trials, ${ }^{9}$ the two doses of ranibizumab have equivalent efficacy in the treatment of DME. Ranibizumab at $0.3 \mathrm{mg}$ may result in lower drug concentration in systemic circulation, thereby reducing the risk of cardiovascular dysfunctions elicited by systemic inhibition of VEGF in patients with DME. ${ }^{66}$ The FDA therefore approved 0.3 $\mathrm{mg}$ /injection as the standard, long-term administration of ranibizumab in DME treatment. ${ }^{9}$ However, the results of other clinical trials $\mathrm{s}^{67,68}$ indicate that $0.5 \mathrm{mg}$ ranibizumab used at a frequency less than once a month or in various PRN regimens could be considered, particularly in DME patients with a lower baseline VA.

\section{Comparison of conbercept to ranibizumab}

In $2017, \mathrm{Xu}$ et al ${ }^{69}$ reported a retrospective study comparing the efficacy of IVC with IVR in DME treatment. Sixty-two Chinese patients with DME were recruited, 32 of whom received IVC and the others IVR. The therapeutic regimen was once a month for 3 months followed by PRN therapy. After 1 year, both groups showed apparent BCVA improvements (IVC 9.3 \pm 5.2 letter scores, IVR 8.9 \pm 4.4 letter scores, $P=0.756$ ) and CRT reductions (IVC 138.4 $\pm 97.7 \mu \mathrm{m}$, IVR $145.2 \pm 72.5 \mu \mathrm{m}, P=0.748)$, however, no statistically significant differences were detected between the groups (Table 3). These data suggest that both conbercept and ranibizumab are effective in treating DME and can achieve similar efficacy. However, the number of injections in the IVR group was significantly more than that in the IVC group (IVR 7.2 \pm 1.0 injections/eye, IVC $6.6 \pm 0.9$ injections/ eye; $P=0.027$, IVR vs IVC) (Table 3 ). The lower injection frequency of IVC may indicate a lower risk of injectionassociating complications and greater cost-effectiveness of conbercept.

\section{Discussion and conclusion}

Aflibercept and conbercept both belong to the group of recombinant decoy receptors to VEGF. They sequester free VEGF from mediating signal transduction through its cognate receptors, thereby blocking the pro-inflammatory, hyper-permeable, and pro-angiogenic effects of VEGF in a similar manner. Both drugs have been shown to be effective and safe for DME treatment.

Aflibercept exhibits greater therapeutic efficacy, including greater VA improvement and anatomic restoration, than traditional laser therapy. Further, it displays advantages over $\mathrm{mAb}$ drugs, such as bevacizumab and ranibizumab, in improving VA and ameliorating macular edema particularly in patients with initial VA less than 20/50, as well as those with PDR. However, aflibercept is the most expensive among the three clinically available anti-VEGF drugs. During 1-year treatment of DME, the incremental cost-effectiveness ratio of aflibercept is higher than that of bevacizumab, though it is still lower than that of ranibizumab. ${ }^{70}$ Treatment cost is another factor to consider especially when it is at odds with therapeutic efficacy. The sequential treatment of long-acting dexamethasone implant followed by IVA could be an option since it maintains similar efficacy as IVA alone, while reducing treatment cost.

On the other hand, conbercept, as a new anti-VEGF drug that is designed, developed, and manufactured in People's Republic of China, has not yet been widely applied in clinics 
around the world. Even though the structural and functional merits of conbercept have been demonstrated in laboratories and it has been shown to be more cost-effective than ranibizumab in a small-sized clinical study, ${ }^{69}$ its therapeutic equivalency or superiority to VEGF mAbs has not been demonstrated in large-scale clinical trials. Furthermore, a small-sized clinical trial conducted in People's Republic of China has compared the efficacy of the therapeutic modality combining laser with IVC with that of IVC alone. ${ }^{53}$ The results suggest that the combinatorial therapy may be a promising modality for DME due to its cost-effectiveness and reduced risk of adverse events, while maintaining equal efficacy. Nonetheless, confirmation from large-scale, standard, and stringently-controlled clinical trials is necessary before laser and IVC combinatorial therapy can be applied routinely in clinics.

\section{Acknowledgments}

This study was supported by grants from the National Natural Science Foundation of China (81670875 to XL); the key projects of Tianjin Municipal Science and Technology Commission (15JCZDJC34500 to XL; 17JCZDJC35600 to YZ); the training plan in 2017 for young and middle-aged backbone talents of colleges and universities in Tianjin to YZ; the High-level Innovative Talent Program for Distinguished Scholars (YDYYRCXM-B2018-02 to YZ).

We would like to express our gratitude to Drs Yunshan Cao and Ruihua Wei, Mr Boteng Gong, Ms Mianmian Wu, and Ms Fang Guo for their assistance during the literature search and manuscript revisions. This study did not obtain any support or sponsorship from pharmaceutical companies. None of the funders of this research had any influence on the design of the study, the search, analysis, and interpretation of the literature, or the writing of the manuscript.

\section{Disclosure}

The authors report no conflicts of interest in this work.

\section{References}

1. Tan GS, Cheung N, Simó R, Cheung GC, Wong TY. Diabetic macular oedema. Lancet Diabetes Endocrinol. 2017;5(2):143-155.

2. Varma R, Bressler NM, Doan QV, et al. Prevalence of and risk factors for diabetic macular edema in the United States. JAMA Ophthalmol. 2014;132(11):1334-1340.

3. Chen L, Magliano DJ, Zimmet PZ. The worldwide epidemiology of type 2 diabetes mellitus - present and future perspectives. Nat Rev Endocrinol. 2011;8(4):228-236.

4. Shrestha GS, Kaiti R. Visual functions and disability in diabetic retinopathy patients. J Optom. 2014;7(1):37-43.

5. Ghanchi F. Diabetic Retinopathy Guidelines Working G. The Royal College of Ophthalmologists' clinical guidelines for diabetic retinopathy: a summary. Eye. 2013;27(2):285-287.
6. Photocoagulation for diabetic macular edema. Early Treatment Diabetic Retinopathy Study report number 1. Early Treatment Diabetic Retinopathy Study research group. Arch Ophthalmol. 1985;103(12): 1796-1806.

7. Nguyen QD, Brown DM, Marcus DM, et al. Ranibizumab for diabetic macular edema: results from 2 phase III randomized trials: RISE and RIDE. Ophthalmology. 2012;119(4):789-801.

8. Romero-Aroca P, Reyes-Torres J, Baget-Bernaldiz M, Blasco-Suñe C. Laser treatment for diabetic macular edema in the 21st century. Curr Diabetes Rev. 2014;10(2):100-112.

9. Brown DM, Nguyen QD, Marcus DM, et al. Long-term outcomes of ranibizumab therapy for diabetic macular edema: the 36-month results from two phase III trials: RISE and RIDE. Ophthalmology. 2013;120(10): 2013-2022.

10. Bhagat N, Grigorian RA, Tutela A, Zarbin MA. Diabetic macular edema: pathogenesis and treatment. Surv Ophthalmol. 2009;54(1):1-32.

11. Boyer DS, Yoon YH, Belfort R, et al. Three-year, randomized, sham-controlled trial of dexamethasone intravitreal implant in patients with diabetic macular edema. Ophthalmology. 2014;121(10): 1904Jr-1914Jr.

12. Campochiaro PA, Brown DM, Pearson A, et al. Long-term benefit of sustained-delivery fluocinolone acetonide vitreous inserts for diabetic macular edema. Ophthalmology. 2011;118(4):626-635.

13. Sohn HJ, Han DH, Kim IT, et al. Changes in aqueous concentrations of various cytokines after intravitreal triamcinolone versus bevacizumab for diabetic macular edema. Am J Ophthalmol. 2011;152(4):686-694.

14. Brooks HL, Caballero S, Newell CK, et al. Vitreous levels of vascular endothelial growth factor and stromal-derived factor 1 in patients with diabetic retinopathy and cystoid macular edema before and after intraocular injection of triamcinolone. Arch Ophthalmol. 2004;122(12): 1801-1807.

15. Campochiaro PA, Brown DM, Pearson A, et al. Sustained delivery fluocinolone acetonide vitreous inserts provide benefit for at least 3 years in patients with diabetic macular edema. Ophthalmology. 2012;119(10): 2125-2132.

16. Brown DM, Schmidt-Erfurth U, do DV, et al. Intravitreal Aflibercept for Diabetic Macular Edema: 100-Week Results From the VISTA and VIVID Studies. Ophthalmology. 2015;122(10):2044-2052.

17. Schmidt-Erfurth U, Lang GE, Holz FG, et al. Three-year outcomes of individualized ranibizumab treatment in patients with diabetic macular edema: the RESTORE extension study. Ophthalmology. 2014;121(5): $1045-1053$.

18. Bahrami B, Hong T, Gilles MC, Chang A. Anti-VEGF Therapy for Diabetic Eye Diseases. Asia Pac J Ophthalmol. 2017;6(6):535-545.

19. Holash J, Davis S, Papadopoulos N, et al. VEGF-Trap: a VEGF blocker with potent antitumor effects. Proc Natl Acad Sci U S A. 2002;99(17): 11393-11398.

20. Papadopoulos N, Martin J, Ruan Q, et al. Binding and neutralization of vascular endothelial growth factor (VEGF) and related ligands by VEGF Trap, ranibizumab and bevacizumab. Angiogenesis. 2012;15(2): $171-185$.

21. Yang LP, Mckeage K. Intravitreal aflibercept (Eylea(®)): a review of its use in patients with macular oedema secondary to central retinal vein occlusion. Drugs Aging. 2014;31(5):395-404.

22. Miller JW, Le Couter J, Strauss EC, Ferrara N. Vascular endothelial growth factor a in intraocular vascular disease. Ophthalmology. 2013; 120(1):106-114.

23. Rudge JS, Holash J, Hylton D, et al. VEGF Trap complex formation measures production rates of VEGF, providing a biomarker for predicting efficacious angiogenic blockade. Proc Natl Acad Sci U S A. 2007; 104(47): 18363-18370.

24. Lee SH, Jeong D, Han YS, Baek MJ. Pivotal role of vascular endothelial growth factor pathway in tumor angiogenesis. Ann Surg Treat Res. 2015; 89(1):1-8.

25. Veikkola T, Karkkainen M, Claesson-Welsh L, Alitalo K. Regulation of angiogenesis via vascular endothelial growth factor receptors. Cancer Res. 2000;60(2):203-212. 
26. Christoforidis JB, Carlton MM, Knopp MV, Hinkle GH. PET/CT imaging of I-124-radiolabeled bevacizumab and ranibizumab after intravitreal injection in a rabbit model. Invest Ophthalmol Vis Sci. 2011; 52(8):5899-5903.

27. Christoforidis JB, Williams MM, Kothandaraman S, et al. Pharmacokinetic properties of intravitreal I-124-aflibercept in a rabbit model using PET/CT. Curr Eye Res. 2012;37(12):1171-1174.

28. Stewart MW, Rosenfeld PJ, Penha FM, et al. Pharmacokinetic rationale for dosing every 2 weeks versus 4 weeks with intravitreal ranibizumab, bevacizumab, and aflibercept (vascular endothelial growth factor Trap-eye). Retina. 2012;32(3):434-457.

29. Cheng YD, Yang H, Chen GQ, Zhang ZC. Molecularly targeted drugs for metastatic colorectal cancer. Drug Des Devel Ther. 2013;7: $1315-1322$

30. Sharma T, Dhingra R, Singh S, et al. Aflibercept: a novel VEGF targeted agent to explore the future perspectives of anti-angiogenic therapy for the treatment of multiple tumors. Mini Rev Med Chem. 2013;13(4): 530-540.

31. Luo JC, Yamaguchi S, Shinkai A, Shitara K, Shibuya M. Significant expression of vascular endothelial growth factor/vascular permeability factor in mouse ascites tumors. Cancer Res. 1998;58(12):2652-2660.

32. Suto K, Yamazaki Y, Morita T, Mizuno H. Crystal structures of novel vascular endothelial growth factors (VEGF) from snake venoms: insight into selective VEGF binding to kinase insert domain-containing receptor but not to fms-like tyrosine kinase-1. J Biol Chem. 2005;280(3): 2126-2131.

33. Zhang M, Zhang J, Yan M, et al. Recombinant anti-vascular endothelial growth factor fusion protein efficiently suppresses choridal neovasularization in monkeys. Mol Vis. 2008;14:37-49.

34. Zhang M, Yu D, Yang C, et al. The pharmacology study of a new recombinant human VEGF receptor-fc fusion protein on experimental choroidal neovascularization. Pharm Res. 2009;26(1):204-210.

35. Shinkai A, Ito $\mathrm{M}$, Anazawa $\mathrm{H}$, et al. Mapping of the sites involved in ligand association and dissociation at the extracellular domain of the kinase insert domain-containing receptor for vascular endothelial growth factor. J Biol Chem. 1998;273(47):31283-31288.

36. Fuh G, Li B, Crowley C, Cunningham B, Wells JA. Requirements for binding and signaling of the kinase domain receptor for vascular endothelial growth factor. J Biol Chem. 1998;273(18):11197-11204.

37. Li X, Xu G, Wang Y, et al. Safety and efficacy of conbercept in neovascular age-related macular degeneration: results from a 12-month randomized phase 2 study: AURORA study. Ophthalmology. 2014;121(9): 1740-1747.

38. Yu DC, Lee JS, Yoo JY, et al. Soluble vascular endothelial growth factor decoy receptor FP3 exerts potent antiangiogenic effects. Mol Ther. 2012; 20(5):938-947.

39. Bakri SJ, Snyder MR, Reid JM, Pulido JS, Singh RJ. Pharmacokinetics of intravitreal bevacizumab (Avastin). Ophthalmology. 2007;114(5): $855-859$.

40. Li H, Lei N, Zhang M, et al. Pharmacokinetics of a long-lasting antiVEGF fusion protein in rabbit. Exp Eye Res. 2012;97(1):154-159.

41. Sinapis CI, Routsias JG, Sinapis AI, et al. Pharmacokinetics of intravitreal bevacizumab (Avastin ${ }^{\circledR}$ ) in rabbits. Clin Ophthalmol. 2011;5: 697-704.

42. Stewart MW, Rosenfeld PJ. Predicted biological activity of intravitreal VEGF Trap. Br J Ophthalmol. 2008;92(5):667-668.

43. do DV, Nguyen QD, Shah SM, et al. An exploratory study of the safety, tolerability and bioactivity of a single intravitreal injection of vascular endothelial growth factor Trap-Eye in patients with diabetic macular oedema. Br J Ophthalmol. 2009;93(2):144-149.

44. Campos Polo R, Rubio Sánchez C, García Guisado DM, Díaz Luque MJ. Aflibercept for clinically significant diabetic macular edema: 12-month results in daily clinical practice. Clin Ophthalmol. 2018;12:99-104.

45. Andrade GC, Dias JR, Maia A, et al. Intravitreal injections of zivaflibercept for diabetic macular edema: a pilot study. Retina. 2016;36(9): $1640-1645$.
46. Li F, Zhang L, Wang Y, et al. One-Year Outcome of Conbercept Therapy for Diabetic Macular Edema. Curr Eye Res. 2018;43(2):218-223.

47. do DV, Schmidt-Erfurth U, Gonzalez VH, et al. The DA VINCI Study: phase 2 primary results of VEGF Trap-Eye in patients with diabetic macular edema. Ophthalmology. 2011;118(9):1819-1826.

48. do DV, Nguyen QD, Boyer D, et al. One-year outcomes of the da Vinci Study of VEGF Trap-Eye in eyes with diabetic macular edema. Ophthalmology. 2012;119(8):1658-1665.

49. Gonzalez VH, Boyer DS, Schmidt-Erfurth U, et al. Microperimetric assessment of retinal sensitivity in eyes with diabetic macular edema from a phase 2 study of intravitreal aflibercept. Retina. 2015;35(4): 687-694.

50. Korobelnik JF, do DV, Schmidt-Erfurth U, et al. Intravitreal aflibercept for diabetic macular edema. Ophthalmology. 2014;121(11):2247-2254.

51. Heier JS, Korobelnik JF, Brown DM, et al. Intravitreal Aflibercept for Diabetic Macular Edema: 148-Week Results from the VISTA and VIVID Studies. Ophthalmology. 2016;123(11):2376-2385.

52. Wykoff CC, Le RT, Khurana RN, et al. Outcomes With As-Needed Aflibercept and Macular Laser Following the Phase III VISTA DME Trial: ENDURANCE 12-Month Extension Study. Am J Ophthalmol. 2017;173:56-63.

53. Xu Y, Rong A, Bi Y, Xu W. Intravitreal Conbercept Injection with and without Grid Laser Photocoagulation in the Treatment of Diffuse Diabetic Macular Edema in Real-Life Clinical Practice. J Ophthalmol. 2016;2016:2143082.

54. Qiao G, Dong WJ, Dai Y, Jiang ZH, Guo HK. Diabetic macular edema in proliferative stage treated with anti-vascular endothelial growth factor agent and triamcinolone acetonide by laser-based strategies. Int $J$ Ophthalmol. 2017;10(7):1113-1119.

55. Hirano T, Toriyama Y, Iesato Y, et al. Effect of leaking perifoveal microaneurysms on resolution of diabetic macular edema treated by combination therapy using anti-vascular endothelial growth factor and short pulse focal/grid laser photocoagulation. Jpn J Ophthalmol. 2017; 61(1):51-60.

56. Payne JF, Wykoff CC, Clark WL, et al. Randomized Trial of Treat and Extend Ranibizumab with and without Navigated Laser for Diabetic Macular Edema: TREX-DME 1 Year Outcomes. Ophthalmology. 2017; 124(1):74-81.

57. Solaiman KA, Diab MM, Abo-Elenin M. Intravitreal bevacizumab and/or macular photocoagulation as a primary treatment for diffuse diabetic macular edema. Retina. 2010;30(10):1638-1645.

58. Arevalo JF, Lasave AF, Wu L, et al. Intravitreal bevacizumab plus grid laser photocoagulation or intravitreal bevacizumab or grid laser photocoagulation for diffuse diabetic macular edema: results of the Panamerican Collaborative Retina Study Group at 24 months. Retina. 2013; 33(2):403-413.

59. Neubauer AS, Haritoglou C, Ulbig MW. Cost Comparison of Licensed Intravitreal Therapies for Insufficiently Anti-VEGF Responding Fovea Involving Diabetic Macular Edema in Germany. Klin Monbl Augenheilkd. Epub 2018 Feb 16.

60. Hernández-Bel L, Cervera-Taulet E, Navarro-Palop C, Castro-Navarro V, Chiarri-Toumit C, Montero-Hernández J. Sequential Dexamethasone and Aflibercept Treatment in Patients with Diabetic Macular Edema: Structural and Functional Outcomes at 52 Weeks. Ophthalmologica. Epub 2018 Jul 11.

61. Diabetic Retinopathy Clinical Research Network, Wells JA, Glassman AR, Ayala AR, et al. Aflibercept, bevacizumab, or ranibizumab for diabetic macular edema. N Engl J Med. 2015;372(13):1193-1203.

62. Wells JA, Glassman AR, Ayala AR, et al. Aflibercept, Bevacizumab, or Ranibizumab for Diabetic Macular Edema: Two-Year Results from a Comparative Effectiveness Randomized Clinical Trial. Ophthalmology. 2016;123(6):1351-1359.

63. Wells JA, Glassman AR, Jampol LM, et al. Association of Baseline Visual Acuity and Retinal Thickness With 1-Year Efficacy of Aflibercept, Bevacizumab, and Ranibizumab for Diabetic Macular Edema. JAMA Ophthalmol. 2016;134(2):127-134. 
64. Jampol LM, Glassman AR, Bressler NM, et al. Anti-Vascular Endothelial Growth Factor Comparative Effectiveness Trial for Diabetic Macular Edema: Additional Efficacy Post Hoc Analyses of a Randomized Clinical Trial. JAMA Ophthalmol. 2016;134(12):1429-1434.

65. Bressler SB, Liu D, Glassman AR, et al. Change in Diabetic Retinopathy Through 2 Years: Secondary Analysis of a Randomized Clinical Trial Comparing Aflibercept, Bevacizumab, and Ranibizumab. JAMA Ophthalmol. 2017;135(6):558-568.

66. Hernández C, Candell-Riera J, Ciudin A, Francisco G, Aguadé-Bruix S, Simó R. Prevalence and risk factors accounting for true silent myocardial ischemia: a pilot case-control study comparing type 2 diabetic with non-diabetic control subjects. Cardiovasc Diabetol. 2011;10:9.

67. Mitchell P, Bandello F, Schmidt-Erfurth U, et al. The RESTORE study: ranibizumab monotherapy or combined with laser versus laser monotherapy for diabetic macular edema. Ophthalmology. 2011;118(4): 615-625.
68. Elman MJ, Bressler NM, Qin H, et al. Expanded 2-year follow-up of ranibizumab plus prompt or deferred laser or triamcinolone plus prompt laser for diabetic macular edema. Ophthalmology. 2011;118(4): 609-614.

69. Xu Y, Rong A, Xu W, Niu Y, Wang Z. Comparison of 12-month therapeutic effect of conbercept and ranibizumab for diabetic macular edema: a real-life clinical practice study. BMC Ophthalmol. 2017;17(1):158.

70. Ross EL, Hutton DW, Stein JD, et al. Cost-effectiveness of Aflibercept, Bevacizumab, and Ranibizumab for Diabetic Macular Edema Treatment: Analysis From the Diabetic Retinopathy Clinical Research Network Comparative Effectiveness Trial. JAMA Ophthalmol. 2016; 134(8):888-896.

\section{Publish your work in this journal}

Drug Design, Development and Therapy is an international, peerreviewed open-access journal that spans the spectrum of drug design and development through to clinical applications. Clinical outcomes, patient safety, and programs for the development and effective, safe, and sustained use of medicines are the features of the journal, which has also been accepted for indexing on PubMed Central. The manuscript management system is completely online and includes a very quick and fair peer-review system, which is all easy to use. Visit http://www.dovepress.com/testimonials.php to read real quotes from published authors.

Submit your manuscript here: http://www.dovepress.com/drug-design-development-and-therapy-journal 